\title{
Apoptosis-inducing effect of erlotinib is potentiated by 3,3'- diindolylmethane in vitro and in vivo using an orthotopic model of pancreatic cancer
}

\author{
Shadan Ali ${ }^{1}$, Sanjeev Banerjee ${ }^{2}$, Aamir Ahmad ${ }^{2}$, Bassel F. El-Rayes ${ }^{1}$, Philip A. Philip ${ }^{1}$, and \\ Fazlul H. Sarkar ${ }^{2}$ \\ ${ }^{1}$ Division of Hematology/Oncology, Wayne State University School of Medicine, Detroit, Michigan \\ 2Department of Pathology, Karmanos Cancer Institute, Wayne State University School of \\ Medicine, Detroit, Michigan
}

\section{Abstract}

Blockade of epidermal growth factor receptor (EGFR) by EGFR tyrosine kinase inhibitors is insufficient for effective antitumor activity because of independently activated survival pathways. A multitargeted approach may therefore improve the outcome of anti-EGFR therapies. In the present study, we determined the effects of 3,3'-diindolyl-methane (Bioresponse BR-DIM referred to as B-DIM), a formulated DIM with greater bioavailability on cell viability and apoptosis with erlotinib in vitro and in vivo using an orthotopic animal tumor model. BxPC-3 and MIAPaCa cells with varying levels of EGFR and nuclear factor- $\mathrm{KB}$ (NF-KB) DNA-binding activity were treated with B-DIM $(20 \mu \mathrm{mol} / \mathrm{L})$, erlotinib $(2 \mu \mathrm{mol} / \mathrm{L})$, and the combination. Cell survival and apoptosis was assessed by 3-(4,5-dimethylthiazol-2-yl)-2,5-diphenyltetrazolium bromide and histone-DNA ELISA. Electrophoretic mobility shift assay was used to evaluate NF-KB DNA-binding activity. We found significant reduction in cell viability by both 3-(4,5-dimethylthiazol-2-yl)-2,5diphenyltetrazolium bromide and clonogenic assays, induction of apoptosis, down-regulation of EGFR phosphorylation, NF-KB DNA-binding activity, and expression of antiapoptotic genes in BxPC-3 cells when treated with the combination of erlotinib and B-DIM compared with either agent alone. In contrast, no such effect was observed in MIAPaCa cells by similar treatment. Most importantly, these in vitro results were recapitulated in animal model showing that B-DIM in combination with erlotinib was much more effective as an antitumor agent compared with either agent alone. These results suggest that the utilization of B-DIM could be a useful strategy for achieving better treatment outcome in patients with activated status of EGFR and NF-KB in their tumors.

\section{Introduction}

Human pancreatic cancer remains one of the few cancers with a very poor prognosis. More than 30,000 patients die of this disease every year in the United States (1). The vast majority of patients present with gross metastases or micrometastases requiring effective drug

copyright (C) 2008 American Association for Cancer Research.

Requests for reprints: Fazlul H. Sarkar, Department of Pathology, Karmanos Cancer Institute, Wayne State University School of Medicine, 740 Hudson Webber Cancer Research Center, Detroit, MI 48201. Phone: 313-576-8327; Fax: 313-576-8389. fsarkar@med.wayne.edu.

S. Ali and S. Banerjee contributed equally to this work.

Disclosure of Potential Conflicts of Interest

No potential conflicts of interest were disclosed 
therapies. To date, there has been no significant effect on the natural history of this disease by conventional cytotoxic therapy, including the use of gemcitabine (2).

Various research approaches address the lack of chemo-sensitivity in human pancreatic cancer. With the introduction of targeted drugs, several studies were launched to test those agents in patients with pancreatic cancer. The epidermal growth factor receptor (EGFR) pathway is activated in several human malignancies including pancreatic cancer $(3,4)$. Inactivation of the EGFR pathway by EGFR-related tyrosine kinase inhibitor, erlotinib, showed some promise in a large phase III study when combined with gemcitabine (5). However, the benefit of the treatment over gemcitabine (a standard) was very modest. Two strategies that will improve the outcome of EGFR blockade include the addition of agents that target other signaling pathways involved in cell survival and the identification of biomarkers of sensitivity to EGFR blockers. To date, no such molecular markers have been determined for pancreatic cancer.

The dietary indoles (indole-3-carbinol; I3C) present in the Brassica plants, including turnips, kale, broccoli, cabbage, Brussels sprouts, and cauliflower, have shown to be protective against several cancers $(6,7)$. I3C is an autolysis product of glucosinolate found in Brassica food plants with antitumor activity in vitro and in vivo by inducing apoptotic cell death (812). I3C is chemically unstable in an acidic environment and is rapidly converted in the stomach to a variety of condensation products. Among those, 3,3'-diindolylmethane (DIM) is a major acid condensation product of $\mathrm{I} 3 \mathrm{C}$ (13). It has been shown that $\mathrm{I} 3 \mathrm{C}$ and its dimeric product DIM possess anticarcinogenic effects in experimental animals and inhibit the growth of human cancer cells $(14,15)$. These findings led to a significant interest in the past few years to explore the potential utility of DIM as a chemopreventive agent (15-17). We have recently found that DIM inhibits cell growth, invasion, and angiogenesis of prostate cancer cells both in vitro and in vivo $(18,19)$. However, the molecular mechanism(s) of the antiproliferative and anticancer effects of DIM in pancreatic cancer has not been documented.

Previous studies have shown that I3C and DIM inhibit EGFR and phosphatidylinositol 3kinase/Akt signaling pathways, which are important signal transduction path-ways in cells and play a critical role in controlling cell survival and apoptosis. It has been shown that Akt, a serine/threonine kinase, regulates nuclear factor- $\mathrm{KB}(\mathrm{NF}-\mathrm{KB})$ activation directly through activation of IKK or phosphorylation of RelA $(20,21)$, and as such, NF-KB is a key regulator of genes involved in proliferation and inhibition of apoptosis $(22,23)$. NF-KB is constitutively activated in most human pancreatic cancer tissues and cell lines but not in normal tissues (24). Moreover, it is known that EGFR is overexpressed in pancreatic cancer and activates NF- $\mathrm{KB}$, which in turn activates cyclooxygenase-2 (COX-2), leading to the production of prostaglandin $\mathrm{E}_{2}\left(\mathrm{PGE}_{2}\right)$, which is known to activate the EGFR pathway through a feedback mechanism (25). There are also other mechanisms involved in the pathway reported by Pino et al. (26), showing that $\mathrm{PGE}_{2}$ drives COX-2 expression through a mechanism involving activation of the $\mathrm{PGE}_{2}$ receptor (26). Resistance to cytotoxic therapy has been partly associated with constitutive activation of NF-KB (27). Studies from our laboratory and others have shown that I3C and DIM are potent inducers of apoptosis, which could be due to the inhibition of Akt and NF-KB in several cancer cells, suggesting that I3C or DIM could serve as a therapeutic agent $(8,9,18,28,29)$. However, similar studies have not been reported in pancreatic cancer. Based on studies from our laboratory and others, we hypothesized that B-DIM (Bioresponse BR-DIM) will inhibit EGFR and NF-KB leading to the inactivation of downstream genes and in turn will lead to sensitization of pancreatic cancer cells to erlotinib-induced inhibition of cell viability and induction of apoptosis. We further hypothesized that the combined effects of B-DIM and erlotinib will be cell line specific based on the molecular signature with respect to EGFR expression and NF-KB 
activation. Therefore, the present study was undertaken to determine whether B-DIM could sensitize pancreatic cancer cells to erlotinib-induced killing in vitro as well in vivo using orthotopic model of pancreatic tumors and also assessed whether inactivation of NF-KB was associated with the biological activity. Furthermore, the molecular effects of B-DIM on downstream signaling molecules were determined to better understand the mechanism of action of B-DIM in cells treated with erlotinib with respect to baseline molecular markers such as EGFR and NF-KB.

\section{Materials and Methods}

\section{Cells Culture, Drugs, and Reagents}

Human pancreatic cancer cell lines BxPC-3 and MIAPaCa were chosen for this study based on their constitutive levels of EGFR, COX-2, and NF- $\mathrm{KB}$ activity. BxPC-3 cells were grown in RPMI 1640 and MIAPaCa cells were grown in DMEM supplemented with 10\% fetal bovine serum. Erlotinib and B-DIM (BR-DIM referred to B-DIM, respectively) were the generous gifts from OSI Pharmaceuticals and Dr. Michael Zeligs (Bioresponse), respectively.

\section{Cell Viability Assay}

To test the viability of cells treated with B-DIM, erlotinib, or the combination, BxPC-3 and MIAPaCa cells were plated (3,000-5,000 per well) in a 96-well plate and incubated overnight at $37^{\circ} \mathrm{C}$. We initially tested a range of concentrations for both B-DIM (10-50 $\mu \mathrm{mol} / \mathrm{L})$ and erlotinib $(1-5 \mu \mathrm{mol} / \mathrm{L})$. Based on the initial results, the concentration of B-DIM $(20 \mu \mathrm{mol} / \mathrm{L})$ and erlotinib $(2 \mu \mathrm{mol} / \mathrm{L})$ were chosen for all assays. The effects of B-DIM (20 $\mu \mathrm{mol} / \mathrm{L})$, erlotinib $(2 \mu \mathrm{mol} / \mathrm{L})$, and the combination on BxPC-3 and MIAPaCa cells were determined by the standard 3-(4,5-dimethylthiazol-2-yl)-2,5-diphenyltetrazolium bromide (MTT) assay after $72 \mathrm{~h}$ and was repeated three times. The color intensity was measured by a Tecan microplate fluorometer at $595 \mathrm{~nm}$. DMSO-treated cells were considered to be the untreated control and assigned a value of $100 \%$. In addition to the above assay, we have also done clonogenic assay for assessing the effects of treatment as shown below.

\section{Clonogenic Assay}

To test the survival of cells treated with B-DIM, erlotinib, or the combination, BxPC-3 and MIAPaCa cells were plated (50,000-100,000 per well) in a six-well plate and incubated overnight at $37^{\circ} \mathrm{C}$. After 72 -h exposure to $20 \mu \mathrm{mol} / \mathrm{L}$ B-DIM, $2 \mu \mathrm{mol} / \mathrm{L}$ erlotinib, and the combination, the cells were trypsinized, and the viable cells were counted (trypan blue exclusion) and plated in $100 \mathrm{~mm}$ Petri dishes in a range of 100 to 1,000 cells to determine the plating efficiency as well as assess the effects of treatment on clonogenic survival. The cells were then incubated for $\sim 10$ to 12 days at $37^{\circ} \mathrm{C}$ in a $5 \% \mathrm{CO}_{2} / 5 \% \mathrm{O}_{2} / 90 \% \mathrm{~N}_{2}$ incubator. The colonies were stained with $2 \%$ crystal violet and counted. The surviving fraction was normalized to untreated control cells with respect to clonogenic efficiency, which was $83 \%$ for both BxPC-3 and MIAPaCa cells. In addition to this assay, cells were also treated similarly and plated in soft-agar (soft-agar colony assay) and incubated at $37^{\circ} \mathrm{C}$. The colonies in the soft agar were also counted in all untreated and treated wells after 12 days.

\section{Quantification of Apoptosis by ELISA}

The Cell Death Detection ELISA kit (Roche Applied Science) was used to detect apoptosis in untreated and treated BxPC-3 and MIAPaCa cells. Cells seeded in six-well plates were treated with B-DIM $(20 \mu \mathrm{mol} / \mathrm{L})$, erlotinib $(2 \mu \mathrm{mol} / \mathrm{L})$, or the combination. The cells were trypsinized and $\sim 10,000$ cells were used as described earlier (30). Tecan microplate 
fluorometer was used to measure color intensity at $405 \mathrm{~nm}$. The experiment was repeated three times.

\section{Protein Extraction and Western Blot Analysis}

BxPC-3 and MIAPaCa cells treated with B-DIM $(20 \mu \mathrm{mol} / \mathrm{L})$, erlotinib $(2 \mu \mathrm{mol} / \mathrm{L})$, or the combination for $72 \mathrm{~h}$ were used to evaluate the effects of treatment on survivin, Bcl-2, BclxL, EGFR, EGFR-pTyr ${ }^{1173}$, c-IAP1/2, Src, poly(ADP-ribose) polymerase (PARP), and $\beta$ actin expression. The experiment was carried out for a minimum of three times. Cells were harvested as described previously (30). The samples were loaded on $7 \%$ to $12 \%$ SDSPAGE for separation and electrophoretically transferred to a nitrocellulose membrane. Each membrane was incubated with monoclonal antibody against survivin, Bcl-2, Bcl-xL, Src, cIAP1/2, EGFR, EGFR-pTyr ${ }^{1173}$, PARP, and $\beta$-actin. Blots were incubated with secondary antibodies conjugated with peroxidase. The signal intensity was then measured using chemiluminescent detection system (Pierce).

\section{Electrophoretic Mobility Shift Assay for NF-kB Activation}

To evaluate the effect of B-DIM and erlotinib on BxPC-3 and MIAPaCa cells, the cells were either untreated or treated with B-DIM $(20 \mu \mathrm{mol} / \mathrm{L})$, erlotinib $(2 \mu \mathrm{mol} / \mathrm{L})$, or the combination with a minimum repeat of experiment at least three times for $72 \mathrm{~h}$. The cells or the minced tumor tissue were homogenized using a Dounce homogenizer (Kontes) in $400 \mu \mathrm{L}$ ice-cold lysis buffer as described earlier (30).

Electrophoretic mobility shift assay (EMSA) was done using the Odyssey Infrared Imaging System with NF-KB IRDye-labeled oligonucleotide from LI-COR. The DNA-binding reaction was set up using 5 to $10 \mu \mathrm{g}$ of the nuclear extract as described earlier (30). The samples were loaded and run at $30 \mathrm{~mA}$ for $1 \mathrm{~h}$. The gel was scanned using Odyssey Infrared Imaging System (LI-COR). Equal protein loading was ensured by immunoblotting $10 \mu \mathrm{g}$ nuclear protein with anti-retinoblastoma antibody.

\section{p65 cDNA Transfection}

To determine the effect of $\mathrm{p} 65$ cDNA transfection, BxPC-3 and MIAPaCa cells were plated in six-well plates and incubated for $24 \mathrm{~h}$. The cells were then transfected with $3 \mu \mathrm{g} \mathrm{NF-KB}$ p65 cDNA or the control empty vector by ExGen 500 (Fermentas) for $5 \mathrm{~h}$. The cells were incubated with either erlotinib $(2 \mu \mathrm{mol} / \mathrm{L})$, B-DIM $(20 \mu \mathrm{mol} / \mathrm{L})$, or celecoxib $(5 \mu \mathrm{mol} / \mathrm{L})$ or left untreated for $48 \mathrm{~h}$ to determine the protein level and NF-KB DNA-binding activity. Both cytoplasmic and nuclear proteins were extracted and p65 protein expression was determined by Western blot analysis, and NF-KB DNA-binding activity was determined by EMSA. Cells $(\sim 10,000)$ were also removed, lysed, and detected for apoptosis using the Cell Death Detection ELISA kit.

\section{Determination of $\mathrm{PGE}_{2}$}

For the determination of $\mathrm{PGE}_{2}$ levels, $\mathrm{BxPC}-3$ - and MIAPaCa-transfected cells were treated with very low concentrations of erlotinib $(10 \mathrm{nmol} / \mathrm{L}), \mathrm{B}-\mathrm{DIM}(1 \mu \mathrm{mol} / \mathrm{L})$, and celecoxib $(1$ $\mathrm{nmol} / \mathrm{L}$ ) because the ELISA assay was very sensitive and worked well at the lowest concentration range of $\mathrm{PGE}_{2}$ secreted in the culture medium. Greater than $10 \mathrm{nmol} / \mathrm{L}$ erlotinib, $1 \mu \mathrm{mol} / \mathrm{L}$ B-DIM, and $1 \mathrm{nmol} / \mathrm{L}$ celecoxib caused complete inhibition in the $\mathrm{PGE}_{2}$ secretion; thus, we chose $10 \mathrm{nmol} / \mathrm{L}$ erlotinib, $1 \mu \mathrm{mol} / \mathrm{L} \mathrm{B}$-DIM, and $1 \mathrm{nmol} / \mathrm{L}$ celecoxib. The culture medium was collected and analyzed for $\mathrm{PGE}_{2}$ concentration as suggested by the manufacturer using $\mathrm{PGE}_{2}$ high-sensitivity immunoassay kit (R\&D Systems). 


\section{Experimental Animals}

Female ICR-SCID (6-7 weeks old) mice were purchased from Taconic Farms. The mice received Lab Diet 5021 (Purina Mills).

\section{Orthotopic Implantation of Tumor Cells}

BxPC-3 cells were suspended in PBS. The pancreas of anaesthetized mice was exposed through a midline laparotomy incision and by retraction of the spleen. Cells $(1 \times 10)$ in 15 $\mu \mathrm{L}$ PBS were injected into the parenchyma of the pancreas with a 27 -gauge hypodermic needle and a Hamilton syringe. The abdominal wound was closed using a 4.0 absorbable suture in a running fashion. Based on our previous experience with this model, we found $100 \%$ of animals develop pancreatic tumor over a 14-day period.

\section{Experimental Protocol}

Mice were randomized into the following treatment groups $(n=7)$ : (a) untreated control; (b) only B-DIM (50 mg/kg body weight), intragastric once every day; (c) erlotinib (50 mg/kg body weight), everyday i.p. for 15 days; and (d) B-DIM and erlotinib, following schedule as for individual treatments. All mice were killed on day 3 following last dose of treatment, and their body weight was determined. One part of the tissue was rapidly frozen in liquid nitrogen and stored at $-70^{\circ} \mathrm{C}$ for future use and the other part was fixed in formalin and processed for paraffin block. H\&E staining of fixed tissue section was used to confirm the presence of tumor(s) in each pancreas.

\section{Mice Imaging}

In addition to conventional evaluation using caliper volume and tumor weight, therapeutic response was also evaluated by noninvasive optical imaging assessed by EGFR expression as endpoint tumor biomarker. To achieve this, filter sterilized EGF-IRDye-800CW (EGFR antibody) was delivered via tail vein $(1 \mathrm{nmol} / \mathrm{L}$ per mice). Near infrared fluorescence imaging of live animals was done (day 4 after injection) using Odyssey Infrared Imaging system isofluorane after anesthesia.

\section{Statistical Methods}

Comparisons of treatment outcome were tested for statistical difference by the paired $t$ test. Statistical significance was assumed at $P<0.05$.

\section{Results}

\section{Effects of B-DIM and Erlotinib on the Viability of Pancreatic Cancer Cells}

It is important to note that, during our pilot studies, as indicated in Materials and Methods, different concentrations of B-DIM and erlotinib were used and are presented in Table 1. Moreover, after analyzing the basal level of expression of EGFR, кг-кв, and COX-2, we chose two cell lines having constitutively activated levels of

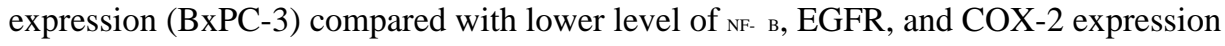
(MIAPaCa). Our results prompted us to select the subsequent concentration of B-DIM and erlotinib as presented below. Cell viability of BxPC-3 and MIAPaCa pancreatic cancer cells treated with B-DIM $(20 \mu \mathrm{mol} / \mathrm{L})$, erlotinib $(2 \mu \mathrm{mol} / \mathrm{L})$, and the combination was determined by the MTT assay, and the data are presented in Fig. 1A and B. Significant inhibition of cell viability was seen in BxPC-3 cells treated with either agent, and this was further enhanced by the combination treatment $(\mathrm{P}=0.0001)$. In addition, we have also tested the effects of treatment on cell viability by clonogenic assay as shown below. Similar treatments of MIAPaCa cells resulted in a significant inhibition of viable cells with B-DIM alone but not when exposed to similar concentrations of B-DIM and erlotinib for the same time, and the 
effect was not enhanced by the combination treatment $(P=0.0890)$. The insensitivity of

MIAPaCa cells to erlotinib is consistent with a recently published report (31).

\section{Inhibition of Cell Growth/Survival by Clonogenic Assay}

To determine the effect of B-DIM and erlotinib on cell growth, cells were treated with each of the single agents or their combination and assessed for cell viability by clonogenic assay. The combination of B-DIM and erlotinib resulted in a significant inhibition of colony formation in BxPC-3 cells when compared with either agent alone (Fig. 2A and B). Similar treatment of MIAPaCa cells (Fig. 2C) showed inhibition of colony formation with B-DIM alone and also the combination, but the effect was not enhanced with the combination treatment as was seen in BxPC-3 cells (Fig. 2A and B). These results were similar to those obtained from the soft-agar assay. Overall, the results from clonogenic assay was consistent with the MTT data as shown in Fig. 1A and B, suggesting that B-DIM had a differential effect between BxPC-3 and MIAPaCa pancreatic cancer cells. The mechanisms of such differences were further investigated, and the results are presented in the following sections, but first we have determined the effects of B-DIM, erlotinib, and the combination on apoptotic cell death.

\section{Induction of Apoptosis by Erlotinib, B-DIM, and the Combination}

The underlying mechanism on the inhibition of cell viability was further studied by determining the apoptotic effects of different treatments using the Cell Death Detection ELISA. The combination of B-DIM and erlotinib resulted in a significant induction of apoptosis only in BxPC-3 cells when compared with the apoptotic effect of either agent alone (Fig. 1C). Similar treatment of MIAPaCa cells showed no induction of apoptosis with the combination (Fig. 1D). These results are consistent with cell viability assay by MTT. Subsequently, we sought to find further evidence of apoptosis as presented below.

\section{B-DIM Enhances Apoptosis Signaling by Erlotinib}

PARP cleavage was determined in BxPC-3 and MIAPaCa cells that were treated with BDIM $(20 \mu \mathrm{mol} / \mathrm{L})$, erlotinib ( $2 \mu \mathrm{mol} / \mathrm{L})$, and the combination (Fig. 3). We found significant amount of PARP (116 kDa) protein cleavage product ( $85 \mathrm{kDa}$ fragment) after 72 -h treatment only in BxPC-3 cells (Fig. 3). In contrast, MIAPaCa cells treated similarly showed only a small cleavage of PARP with B-DIM alone and also in combination but not with erlotinib alone. The induction of apoptosis could be partly due to inactivation of important survival genes; hence, we investigated whether B-DIM, erlotinib, and their combination could affect key survival proteins.

\section{Effect of B-DIM on Molecules Related to Apoptosis}

BxPC-3 and MIAPaCa cells were used to evaluate the effects of B-DIM and/or erlotinib on the expression of survivin, Bcl-2, Bcl-xL, and c-IAP1/2. Expression of Bcl-2, Bcl-xL, survivin, and c-IAP $1 / 2$ proteins was significantly reduced in cells treated with the combination when compared with either agent alone (Fig. 3). There was no influence on antiapoptotic proteins in MIAPaCa cells treated with either agent alone or the combination. These results suggest that B-DIM, erlotinib, and the combination down-regulate key survival proteins and in turn induced apoptotic cell death in BxPC-3 cells but not in MIAPaCa cells. To further determine the molecular mechanism by which B-DIM sensitized BxPC-3 cells to erlotinib-induced inhibition of cell viability and induction of apoptosis, we investigated the role of EGFR and its downstream signaling pathways. 


\section{Effect of B-DIM on the Expression of EGFR Protein}

The expression of EGFR was determined by immunoblotting. No baseline expression of EGFR was found in the MIAPaCa cells. EGFR-expressing BxPC-3 cells showed a significant reduction in the expression of EGFR and phosphorylated EGFR levels when exposed to erlotinib plus B-DIM compared with either agent alone (Fig. 3). It is known that the activation of EGFR could in turn regulate an important transcription factor, NF-KB, which is a known regulator of several survival genes such as survivin, c-IAP1/2, Bcl-2, and $\mathrm{Bcl}-\mathrm{xL}$ (32). Because we found a greater degree of down-regulation of survivin, c-IAP1/2, $\mathrm{Bcl}-2$, and Bcl-xL in BxPC-3 cells treated with B-DIM and erlotinib compared with either agent alone, and because these genes are transcriptionally regulated by NF-KB, we investigated the effect of each treatment on the DNA-binding activity of NF-KB.

\section{B-DIM Inhibits NF-kBDNA-Binding Activity}

The activation of NF- $\mathrm{kB}$, a nuclear transcriptional factor, was assessed in B-DIM-treated and erlotinib-treated cells. There was a significant inhibition of NF-KB activation in BxPC-3 cells exposed to both erlotinib and B-DIM compared with erlotinib alone (Fig. 4A). No such inhibition was shown in the MIAPaCa cells (Fig. 4B). These results suggest that the combination of B-DIM and erlotinib causes greater inhibition of cell growth, induction of apoptosis, inhibition of survival factors, inhibition of EGFR, and inactivation of NF-KB.

Because NF-KB plays important roles in the regulation of prosurvival and antiapoptotic processes, we tested whether overexpression of NF-KB by p65 cDNA transfection could abrogate B-DIM-induced and erlotinib-induced apoptotic processes. Moreover, it is known that NF-KB transcriptionally regulates $\mathrm{COX}-2$, which produces $\mathrm{PGE}_{2}$ and in turn induces cell viability. Thus, we tested whether celecoxib, erlotinib, or B-DIM alone could influence the activity of B-DIM and erlotinib in p65 cDNA transfected cells.

\section{Erlotinib, B-DIM, and Celecoxib Abrogated Activation of NF-kBActivity Stimulated by p65 cDNA Transfection}

Cytoplasmic and nuclear proteins from BxPC-3 and MIAPaCa cells transfected with p65 cDNA and then treated with erlotinib $(2 \mu \mathrm{mol} / \mathrm{L})$, B-DIM $(20 \mu \mathrm{mol} / \mathrm{L})$, or celecoxib $(5 \mu \mathrm{mol} /$ L) or left untreated for $48 \mathrm{~h}$ were subjected to analysis for NF-KB activity as measured by Western blot analysis and EMSA. The results showed that erlotinib, B-DIM, and celecoxib inhibited the p65 protein and NF-KB DNA-binding activity more in BxPC-3 cells compared with untreated cells (Fig. 5A and B) and very little effect was seen in MIAPaCa cells. Importantly, NF-kB p65 cDNA transfection enhanced the NF-kB p65 protein and DNAbinding activity only in BxPC-3 cells to a significant level as shown in Fig. 5A and B. On the other hand, no such changes were observed in the MIAPaCa cells. Because the activation of NF-KB induces COX-2 expression leading to the production of $\mathrm{PGE}_{2}$ that is released into the culture medium, we measured the levels of $\mathrm{PGE}_{2}$ in untransfected and transfected cells treated with erlotinib, B-DIM, and the COX-2 inhibitor celecoxib.

\section{Inhibition of $\mathrm{PGE}_{\mathbf{2}}$ Synthesis in p65 cDNA-Transfected Cells}

We measured the levels of $\mathrm{PGE}_{2}$ in the conditioned medium collected from both BxPC-3 and MIAPaCa cells as an indicator of COX-2 activity. We found a high level of $\mathrm{PGE}_{2}$ secretion by BxPC-3 cells, whereas MIAPaCa cells showed very low levels of $\mathrm{PGE}_{2}$, which is consistent with its low constitutive expression of COX-2 (30). BxPC-3 and MIAPaCa cells were transfected with p65 cDNA followed by treatment with erlotinib $(10 \mathrm{nmol} / \mathrm{L})$, B$\operatorname{DIM}(1 \mu \mathrm{mol} / \mathrm{L})$, or celecoxib $(1 \mathrm{nmol} / \mathrm{L})$ to analyze the levels of $\mathrm{PGE}_{2}$ released into the culture medium (Fig. 5C). No change in $\mathrm{PGE}_{2}$ level was noted when cells were treated with erlotinib alone $(P=0.084)$. However, a significant reduction in $\mathrm{PGE}_{2}$ level was observed in 
BxPC-3 cells treated with B-DIM $(P=0.006)$ and celecoxib $(P=0.005)$. There was a substantial increase in the $\mathrm{PGE}_{2}$ level in p65 cDNA-transfected BxPC-3 cells compared with untransfected cells $(P=0.009)$, suggesting that NF-KB could induce COX-2 expression. However, there was no change in $\mathrm{PGE}_{2}$ level in MIAPaCa cells with any of the agents. Collectively, these results suggest that the production of $\mathrm{PGE}_{2}$ is mediated through the NF$\mathrm{KB}$ and COX-2 pathway and that celecoxib could down-regulate both NF-KB and COX-2. These results were subsequently correlated with the degree of apoptosis (Fig. 5D) as presented below.

\section{Apoptosis through the Inactivation of NF-KB in p65 cDNA-Transfected Cells}

p65 cDNA was transfected into BxPC-3 and MIAPaCa cells and then treated with erlotinib $(2 \mu \mathrm{mol} / \mathrm{L})$, B-DIM $(20 \mu \mathrm{mol} / \mathrm{L})$, or celecoxib $(5 \mu \mathrm{mol} / \mathrm{L})$ for $48 \mathrm{~h}$ (Fig. 5D). The degree of apoptosis in p65 cDNA-transfected BxPC-3 cells treated with erlotinib $(P=0.034)$ was much less compared with untransfected cells treated with erlotinib $(P=0.007)$. Similar results were observed with both B-DIM and celecoxib treatment in BxPC-3 cells. However, in MIAPaCa cells, no such degree of apoptosis was observed. These results suggest that activation of NF-KB by p65 cDNA transfection could abrogate the apoptosis inducing effect of erlotinib, B-DIM, and celecoxib.

\section{B-DIM Augments In vivo Therapeutic Effect of Erlotinib on Primary Tumor}

Potential therapeutic utility of B-DIM and erlotinib combination in SCID mice bearing orthotopically implanted BxPC-3 pancreatic tumor cells was investigated. A dose of $3.5 \mathrm{mg}$ / d B-DIM per mouse was selected for p.o. administration, whereas erlotinib dose $(50 \mathrm{mg} / \mathrm{kg}$ body weight i.p.) was based on previously published reports as shown in Fig. 6A. A total of 28 mice were divided into four groups. To ascertain the efficacy of a single-agent treatment compared with combinations, we determined the mean pancreas weight in all treated groups. Under our experimental conditions, administration of B-DIM by gavage treatment and erlotinib alone caused $20 \%$ and $35 \%$ reduction in tumor weight, respectively, compared with control tumors (Fig. 6C). However, under the experimental conditions, the combination of B-DIM and erlotinib treatment showed significant decrease $(P<0.01)$ in tumor weight compared with untreated control, B-DIM alone, or erlotinib alone treatment group. These results showed, for the first time, the efficacy of combination of B-DIM and erlotinib in the inhibition of pancreatic tumor growth in an orthotopic model.

\section{B-DIM Inhibits NF-kBDNA-Binding Activity In vivo}

The activation of NF-KB was assessed in B-DIM-treated and erlotinib-treated tumor tissues. The results show that NF-KB was down-regulated by B-DIM and erlotinib (Fig. 6B). Fig. 6B (bottom) represents results from all seven mice. These in vivo results were similar to our in vitro findings, suggesting that the inactivation of NF- $\mathrm{KB}$ is, at least, one of the molecular mechanisms by which B-DIM potentiates erlotinib-induced antitumor activity in our experimental animal model.

\section{Fluorescence Imaging of Tumor Size}

To validate tumor size correlation with EGFR receptor status, we used in vivo infrared imaging approach using Li-COR Odyssey as a detection platform. Comparing image intensity from the captured images of randomly selected mice from each group, it was evident that the combination group of mice had lower fluorescent intensity of the IRDye-800CW EGF-targeting agent. These results suggest that relative to single-agent treatments with combination regimen appears to be potent in inhibiting tumor growth, which is consistent with inhibition of tumor size when measured at autopsy (Fig. 6D). 


\section{Discussion}

Pancreatic cancer is a systemic disease that responds very poorly to conventional cytotoxic therapy. This has prompted the search for more novel approaches in therapy, and targeting the EGFR pathway is a major attempt toward the development of newer drugs for this disease. The choice of EGFR has been rationalized based on the relatively high frequency of its activation in pancreatic cancer and its relationship to prognosis. Moreover, preclinical models interrupting EGFR signaling has been associated with a significant antitumor benefit (33). However, results thus far show only a modest benefit for such therapies in patients with pancreatic cancer when anti-EGFR agents were combined with gemcitabine $(5,34)$. Like most other cancers, pancreatic cancer is diagnosed at a time when multiple genetic alterations have driven the carcinogenic process. It is therefore unlikely that a treatment, which targets the EGFR alone, will result in any major effect on the natural history of the vast majority of such patients. Preclinical research has shown that resistance to targeting the EGFR pathway, and hence failure to such therapies, is probably due to redundant and crosstalk pathways that would circumvent any inhibitory effects on downstream signaling of the EGFR pathway. These may include the independent activation of survival pathways, including the activation of Akt, resulting in the activation of NF-KB and its downstream signaling pathway or the activation of downstream molecules by parallel signaling pathways (e.g., Ras/Raf signaling). It is therefore widely recognized that successful therapies for pancreatic cancer will be dependent on the development of rational drug combinations to target multiple gene products and to establish molecular signatures that will predict treatment benefit.

Our approach for a combined targeted therapy strategy for effective antiproliferative and apoptotic signaling blockade was based on the known molecular effects of both erlotinib and B-DIM. The effect of I3C and DIM (B-DIM) was shown in representative cancer cell lines by our laboratory and others with respect to inhibition of Akt (28) and NF-KB activation (35). Our hypothesis was that blocking the activation of Akt and NF-KB would increase apoptosis of human pancreatic cancer cells treated by EGFR blocking agents such as erlotinib, and as such, the combination of these agents would be much more effective compared with either agent alone. Moreover, we hypothesized that there would be a differential effect in human pancreatic tumor cells based on their molecular signature with respect to basal levels of EGFR expression and NF-KB DNA-binding activity in support of "proof-of-principle." Accumulating evidence supports the critical role of NF-kB in carcinogenesis and survival of pancreatic cancer cells $(36,37)$. Additional evidence supports the antiproliferative and proapoptotic benefits of targeting the NF-kB pathway $(38,39)$. However, with the multiple upstream gene mutations that regulate NF-kB activation, effective inhibition of NF-KB activation will require inhibition of multiple signaling pathways.

We investigated two human pancreatic cancer cell lines that were characterized for their expression of EGFR, NF-KB, Akt, and COX-2 for generating data in support of "proof-ofprinciple." The combination of B-DIM and erlotinib was much more pronounced than either drug alone only in BxPC-3 cells in which the EGFR is overexpressed. No such interaction was seen in MIAPaCa cells, which do not express the EGFR. We believe that additional cell lines must be investigated for definitive results where the gene expression profiles of COX-2, EGFR, and NF-KB expression are varied significantly, and as such, these studies are being conducted in our laboratory. To further characterize the downstream molecular events associated with the enhanced apoptosis by combining erlotinib and B-DIM treatment, additional molecular analyses were done. The major hypothesis was to test whether an interaction between the two drugs would be effective in the suppression of NF-KB activation by the blockade of the EGFR tyrosine kinase activity by B-DIM. Indeed, compared with the 
inhibition of NF-KB activation by either erlotinib or B-DIM, the combination had a significant inhibitory role in BxPC-3 cells, which was correlated with the down-regulation of NF-KB and its downstream genes. No such effect was seen in the MIAPaCa cells that lacked expression of the EGFR protein and had minimal basal expression of NF-KB. These results were recapitulated in vivo using the orthotopic model, strengthening our underlying rationale for the treatment of patients with pancreatic cancer using our combination treatment approach. Although we rationalized our hypothesis using an orthotopic model focusing on tumor size at the end of the experiment, further studies are warranted using cell lines that metastasize, and we would like to follow the efficacy in reduction of tumor size by combination treatment over a period. Nonetheless, the results obtained from in vivo study conclusively prove that the combination of B-DIM with erlotinib could be useful in the suppression of NF-KB activation. In addition to the pathways we have mentioned in this report, there are other possible pathways reported by others showing that DIM induces endoplasmic reticulum stress and the extrinsic pathway of apoptosis in pancreatic and other cancer cells (40-42), clearly suggesting that DIM is capable of inactivation of multiple signaling pathways.

The differential effect of the combined treatment of erlotinib and B-DIM between BxPC-3 and MIAPaCa cells and its potential relationship to EGFR and NF-KB activation was determined by the analysis of antiapoptosis-related proteins. Indeed, survivin, Bcl-2, and Bcl-xL expression was significantly reduced by the combination treatment group only in BxPC-3 cells. Other authors have also suggested the modulation of Bcl-2 expression by targeting NF-kB induced transcriptional activation of the Bcl-2 gene (43). Furthermore, it is known that NF-KB activates COX-2 expression and its enzymatic activity, which plays a significant role in cancer cell survival and angiogenesis (44). In the present study, we found that 655 cDNA transfection increased the expression of p65 protein and the DNA-binding activity of NF-KB in BxPC-3 cells. Erlotinib, B-DIM, and celecoxib abrogated the activation of NF-KB stimulated by p65 cDNA transfection, suggesting that all three drugs may reduce the NF-KB DNA-binding activity but only in BxPC-3 cells. However, this inhibition was partly abrogated by 655 cDNA transfection, which provided molecular evidence for the role of NF-KB in mediating the effect of erlotinib, B-DIM, and/or celecoxib. A very minimal effect was seen in MIAPaCa cells transfected with p65 cDNA. In addition, erlotinib, BDIM, or celecoxib treatment of BxPC-3 cells induced apoptosis, but the degree of apoptotic cell death was partly abrogated by p65 cDNA transfection, suggesting that erlotinib, B-DIM, and celecoxib induced inhibition of cell viability and induction of apoptosis is mechanistically linked with the inactivation of NF- $\mathrm{KB}$ and its downstream genes such as COX-2. Again, no such effect was seen in MIAPaCa cells, suggesting the role of NF-kB and COX-2.

A major factor in treatment failure, even with rational design of combination treatment, would not only be due to the molecular makeup of individual cancer cells that vary between patients but also within the same patient in different parts of the tumor or between the primary and metastatic sites. Results of this study clearly show that the benefit of combining erlotinib and B-DIM will be limited to cells that have EGFR pathway activation probably driven by NF-KB activation. Conversely, the cells lacking such molecular signatures, as in the case of MIAPaCa cells, will not benefit from either erlotinib alone or when combined with B-DIM. These findings emphasize the need to develop predictive biomarkers alongside the development of rational targeted combination therapies for pancreatic and other cancers in the future.

In conclusion, this study supports the development of a B-DIM plus erlotinib combination for the treatment of patients diagnosed with pancreatic cancer whose tumors have activation of EGFR and NF-кB. More effective targeting of the NF-KB signaling pathway with the 
combination of erlotinib and B-DIM may be one strategy to enhance apoptosis in pancreatic cancer cells. Moreover, choice of B-DIM as a cotreatment in pancreatic cancer and its application in the clinic is also favorable based on its minimal toxicity.

\section{Acknowledgments}

We sincerely acknowledge the contribution from Guido Foundation.

\section{References}

1. Jemal A, Siegel R, Ward E, et al. Cancer statistics, 2006. CA Cancer J Clin. 2006; 56:106-130. [PubMed: 16514137]

2. El-Rayes BF, Philip PA. A review of systemic therapy for advanced pancreatic cancer. Clin Adv Hematol Oncol. 2003; 1:430-434. [PubMed: 16258429]

3. Tobita K, Kijima H, Dowaki S, et al. Epidermal growth factor receptor expression in human pancreatic cancer: significance for liver metastasis. Int J Mol Med. 2003; 11:305-309. [PubMed: 12579331]

4. Oikawa T, Hitomi J, Kono A, Kaneko E, Yamaguchi K. Frequent expression of genes for receptor tyrosine kinases and their ligands in human pancreatic cancer cells. Int J Pancreatol. 1995; 18:1523. [PubMed: 7594766]

5. Moore M, Goldstein D, Hamm J, et al. Erlotinib plus gemcitabine compared to gemcitabine alone in patients with advanced pancreatic cancer A phase III trial of the National Cancer Institute of Canada Clinical Trials Group [NCIC-CTG]. J Clin Oncol. 2007; 25:1960-1966. [PubMed: 17452677]

6. Steinmetz KA, Potter JD. Vegetables, fruit, and cancer. I Epidemiology. Cancer Causes Control. 1991; 2:325-57. [PubMed: 1834240]

7. Verhoeven DT, Verhagen H, Goldbohm RA, van den Brandt PA, van PG. A review of mechanisms underlying anticarcinogenicity by Brassica vegetables. Chem Biol Interact. 1997; 103:79-129. [PubMed: 9055870]

8. Rahman KM, Aranha O, Glazyrin A, Chinni SR, Sarkar FH. Translocation of Bax to mitochondria induces apoptotic cell death in indole-3-carbinol (I3C) treated breast cancer cells. Oncogene. 2000; 19:5764-5771. [PubMed: 11126363]

9. Rahman KM, Aranha O, Sarkar FH. Indole-3-carbinol (I3C) induces apoptosis in tumorigenic but not in nontumorigenic breast epithelial cells. Nutr Cancer. 2003; 45:101-112. [PubMed: 12791510]

10. Rahman KM, Li Y, Sarkar FH. Inactivation of Akt and NF-KB play important roles during indole-3-carbinol-induced apoptosis in breast cancer cells. Nutr Cancer. 2004; 48:84-94. [PubMed: 15203382]

11. Cover CM, Hsieh SJ, Cram EJ, et al. Indole-3-carbinol and tamoxifen cooperate to arrest the cell cycle of MCF-7 human breast cancer cells. Cancer Res. 1999; 59:1244-1251. [PubMed: 10096555]

12. Kojima T, Tanaka T, Mori H. Chemoprevention of spontaneous endometrial cancer in female Donryu rats by dietary indole-3-carbinol. Cancer Res. 1994; 54:1446-1449. [PubMed: 8137246]

13. Grose KR, Bjeldanes LF. Oligomerization of indole-3-carbinol in aqueous acid. Chem Res Toxicol. 1992; 5:188-193. [PubMed: 1643248]

14. Tiwari RK, Guo L, Bradlow HL, Telang NT, Osborne MP. Selective responsiveness of human breast cancer cells to indole-3-carbinol, a chemopreventive agent. J Natl Cancer Inst. 1994; 86:126-131. [PubMed: 8271295]

15. Hong C, Kim HA, Firestone GL, Bjeldanes LF. 3,3'-Diindolylmethane (DIM) induces a G(1) cell cycle arrest in human breast cancer cells that is accompanied by Sp1-mediated activation of p21(WAF1/CIP1) expression. Carcinogenesis. 2002; 23:1297-1305. [PubMed: 12151347]

16. Firestone GL, Bjeldanes LF. Indole-3-carbinol and 3,3'-diindolylme-thane antiproliferative signaling pathways control cell-cycle gene transcription in human breast cancer cells by regulating promoter-Sp1 transcription factor interactions. J Nutr. 2003; 133:2448S-2455S. [PubMed: 12840223] 
17. Shilling AD, Carlson DB, Katchamart S, Williams DE. 3,3'-diindolyl- methane, a major condensation product of indole-3-carbinol, is a potent estrogen in the rainbow trout. Toxicol Appl Pharmacol. 2001; 170:191- 200. [PubMed: 11162784]

18. Bhuiyan MM, Li Y, Banerjee S, et al. Down-regulation of androgen receptor by 3,3'diindolylmethane contributes to inhibition of cell proliferation and induction of apoptosis in both hormone-sensitive LNCaP and insensitive C4-2B prostate cancer cells. Cancer Res. 2006; 66:10064-10072. [PubMed: 17047070]

19. Kong D, Li Y, Wang Z, Banerjee S, Sarkar FH. Inhibition of angiogenesis and invasion by 3,3'diindolylmethane is mediated by the nuclear factor-kB downstream target genes MMP-9 and uPA that regulated bioavailability of vascular endothelial growth factor in prostate cancer. Cancer Res. 2007; 67:3310-3319. [PubMed: 17409440]

20. Sizemore N, Leung S, Stark GR. Activation of phosphatidylinositol 3-kinase in response to interleukin-1 leads to phosphorylation and activation of the NF-KB p65/RelA subunit. Mol Cell Biol. 1999; 19:4798-4805. [PubMed: 10373529]

21. Meng F, Liu L, Chin PC, D’Mello SR. Akt is a downstream target of NF-K B. J Biol Chem. 2002; 277:29674-29680. [PubMed: 12052823]

22. Grilli M, Chiu JJ, Lenardo MJ. NF-K B and Rel: participants in a multiform transcriptional regulatory system. Int Rev Cytol. 1993; 143:1-62. [PubMed: 8449662]

23. Greten FR, Weber CK, Greten TF, et al. Stat 3 and NF-KB activation prevents apoptosis in pancreatic carcinogenesis. Gastroenterology. 2002; 123:2052-2063. [PubMed: 12454861]

24. Niu J, Li Z, Peng B, Chiao PJ. Identification of an autoregulatory feedback pathway involvinginterleukin-1 $\alpha$ in induction of constitutive NF-KB activation in pancreatic cancer cells. $J$ Biol Chem. 2004; 279:16452-16462. [PubMed: 14679213]

25. Pai R, Soreghan B, Szabo IL, Pavelka M, Baatar D, Tarnawski AS. Prostaglandin $E_{2}$ transactivates EGF receptor: a novel mechanism for promoting colon cancer growth and gastrointestinal hypertrophy. Nat Med. 2002; 8:289-293. [PubMed: 11875501]

26. Pino MS, Nawrocki ST, Cognetti F, Abruzzese JL, Xiong HQ, McConkey DJ. Prostaglandin E 2 drives cyclooxygenase-2 expression via cyclic AMP response element activation in human pancreatic cancer cells. Cancer Biol Ther. 2005; 4:1263-1269. [PubMed: 16319525]

27. Arlt A, Gehrz A, Muerkoster S, et al. Role of NF-kB and Akt/PI3K in the resistance of pancreatic carcinoma cell lines against gemcitabineinduced cell death. Oncogene. 2003; 22:3243-3251. [PubMed: 12761494]

28. Chinni SR, Sarkar FH. Akt inactivation is a key event in indole-3-carbinol-induced apoptosis in PC-3 cells. Clin Cancer Res. 2002; 8:1228-1236. [PubMed: 11948137]

29. Howells LM, Gallacher-Horley B, Houghton CE, Manson MM, Hudson EA. Indole-3-carbinol inhibits protein kinase B/Akt and induces apoptosis in the human breast tumor cell line MDA MB468 but not in the nontumorigenic HBL100 line. Mol Cancer Ther. 2002; 1:1161-1172. [PubMed: 12479697]

30. El-Rayes BF, Ali S, Sarkar FH, Philip PA. Cyclooxygenase-2-dependent and -independent effects of celecoxib in pancreatic cancer cell lines. Mol Cancer Ther. 2004; 3:1421-1426. [PubMed: 15542781]

31. Buck E, Eyzaguirre A, Haley JD, Gibson NW, Cagnoni P, Iwata KK. Inactivation of Akt by the epidermal growth factor receptor inhibitor erlotinib is mediated by HER-3 in pancreatic and colorectal tumor cell lines and contributes to erlotinib sensitivity. Mol Cancer Ther. 2006; 5:20512059. [PubMed: 16928826]

32. Karin M. Nuclear factor-кB in cancer development and progression. Nature. 2006; 441:431-436. [PubMed: 16724054]

33. Kleespies A, Jauch KW, Bruns CJ. Tyrosine kinase inhibitors and gemcitabine: new treatment options in pancreatic cancer? Drug Resist Updat. 2006; 9:1-18. [PubMed: 16621676]

34. Xiong HQ, Rosenberg A, LoBuglio A, et al. Cetuximab, a monoclonal antibody targeting the epidermal growth factor receptor, in combination with gemcitabine for advanced pancreatic cancer: a multicenter phase II Trial. J Clin Oncol. 2004; 22:2610-2616. [PubMed: 15226328] 
35. Li Y, Chinni SR, Sarkar FH. Selective growth regulatory and pro-apoptotic effects of DIM is mediated by AKT and NF-KB pathways in prostate cancer cells. Front Biosci. 2005; 10:236-243. [PubMed: 15574364]

36. Meylan E, Tschopp J, Karin M. Intracellular pattern recognition receptors in the host response. Nature. 2006; 442:39-44. [PubMed: 16823444]

37. Karin M. NF-KB and cancer: mechanisms and targets. Mol Carcinog. 2006; 45:355-361. [PubMed: 16673382]

38. Li L, Aggarwal BB, Shishodia S, Abbruzzese J, Kurzrock R. Nuclear factor-кB and IкB kinase are constitutively active in human pancreatic cells, and their down-regulation by curcumin (diferuloylmethane) is associated with the suppression of proliferation and the induction of apoptosis. Cancer. 2004; 101:2351-2362. [PubMed: 15476283]

39. Li Y, Ellis KL, Ali S, et al. Apoptosis-inducing effect of chemotherapeutic agents is potentiated by soy isoflavone genistein, a natural inhibitor of NF-kB in BxPC-3 pancreatic cancer cell line. Pancreas. 2004; 28:e90-e95. [PubMed: 15097869]

40. Abdelrahim M, Newman K, Vanderlaag K, Samudio I, Safe S. 3,3'-diindolylmethane (DIM) and its derivatives induce apoptosis in pancreatic cancer cells through endoplasmic reticulum stressdependent upregulation of DR5. Carcinogenesis. 2006; 27:717-728. [PubMed: 16332727]

41. Sun S, Han J, Ralph WM Jr. et al. Endoplasmic reticulum stress as a correlate of cytotoxicity in human tumor cells exposed to diindolylmethane in vitro . Cell Stress Chaperones. 2004; 9:76-87. [PubMed: 15270080]

42. Savino JA III, Evans JF, Rabinowitz D, Auborn KJ, Carter TH. Multiple, disparate roles for calcium signaling in apoptosis of human prostate and cervical cancer cells exposed to diindolylmethane. Mol Cancer Ther. 2006; 5:556-563. [PubMed: 16546969]

43. Fahy BN, Schlieman MG, Mortenson MM, Virudachalam S, Bold RJ. Targeting BCL-2 overexpression in various human malignancies through NF-KB inhibition by the proteasome inhibitor bortezomib. Cancer Chemo-ther Pharmacol. 2005; 56:46-54.

44. Wang D, Dubois RN. Prostaglandins and cancer. Gut. 2006; 55:115-122. [PubMed: 16118353] 

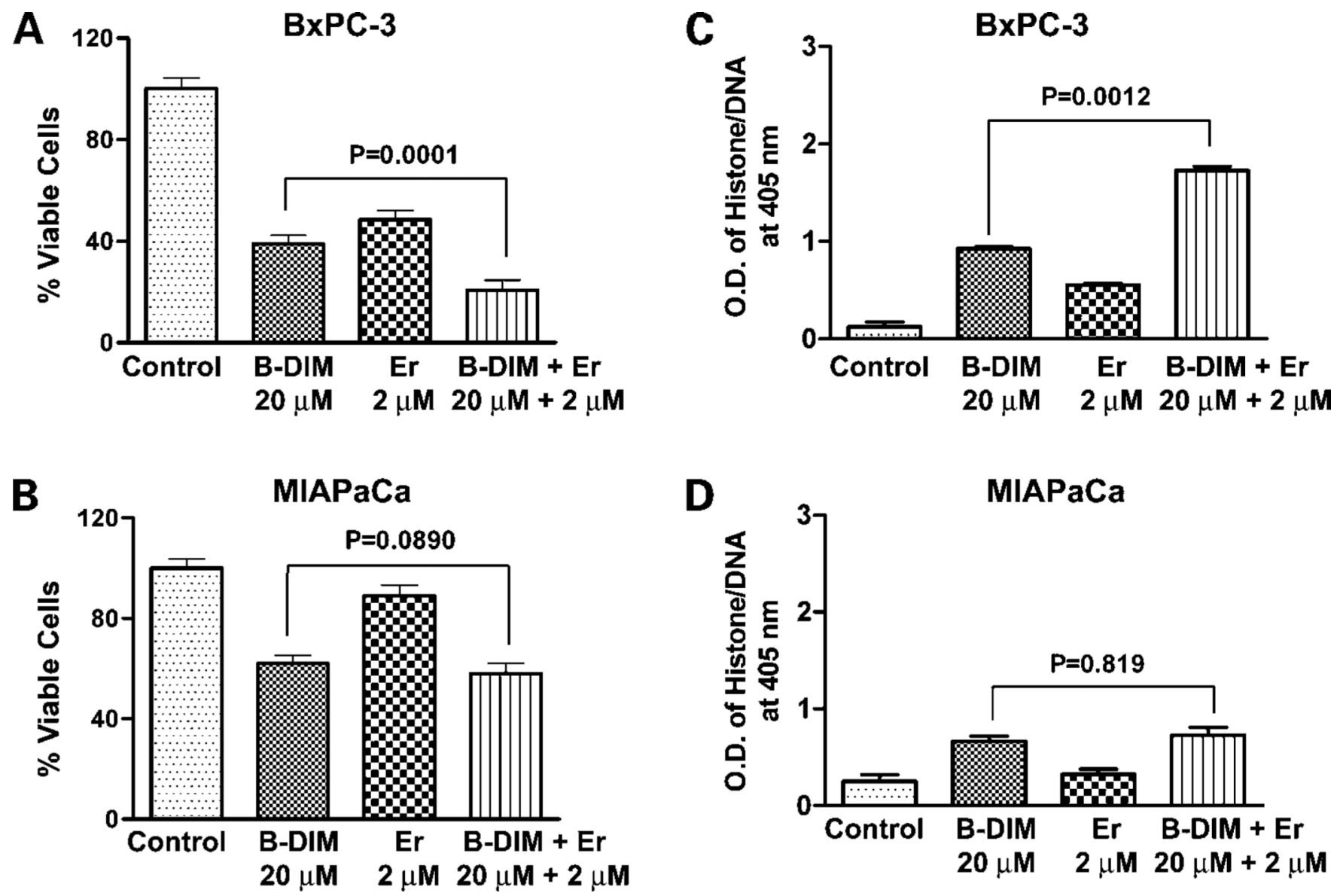

Figure 1.

Cell viability (A and $\mathbf{B}$ ) and induction of apoptosis ( $\mathbf{C}$ and $\mathbf{D})$ of human pancreatic cancer cell lines BxPC-3 and MIAPaCa. Cells treated with B-DIM (20 $\mu \mathrm{mol} / \mathrm{L})$, erlotinib (Er; 2 $\mu \mathrm{mol} / \mathrm{L}$ ), and the combination were evaluated by the MTT assay, and apoptosis was assessed by histone-DNA ELISA method. There was a significant reduction in cell viability (A) and significant potentiation of apoptosis $(\mathbf{C})$ in BxPC-3 cells treated with the combination compared with cells treated with either drug alone. No potentiation in cell viability $(\mathbf{B})$ or induction of apoptosis (D) with the combination was observed in MIAPaCa cells. Results are repeated at least three times. $P$ values represent comparisons between cells treated by either B-DIM or the combination of both drugs using the paired $t$ test for all three experiments. 
A

BxPC-3
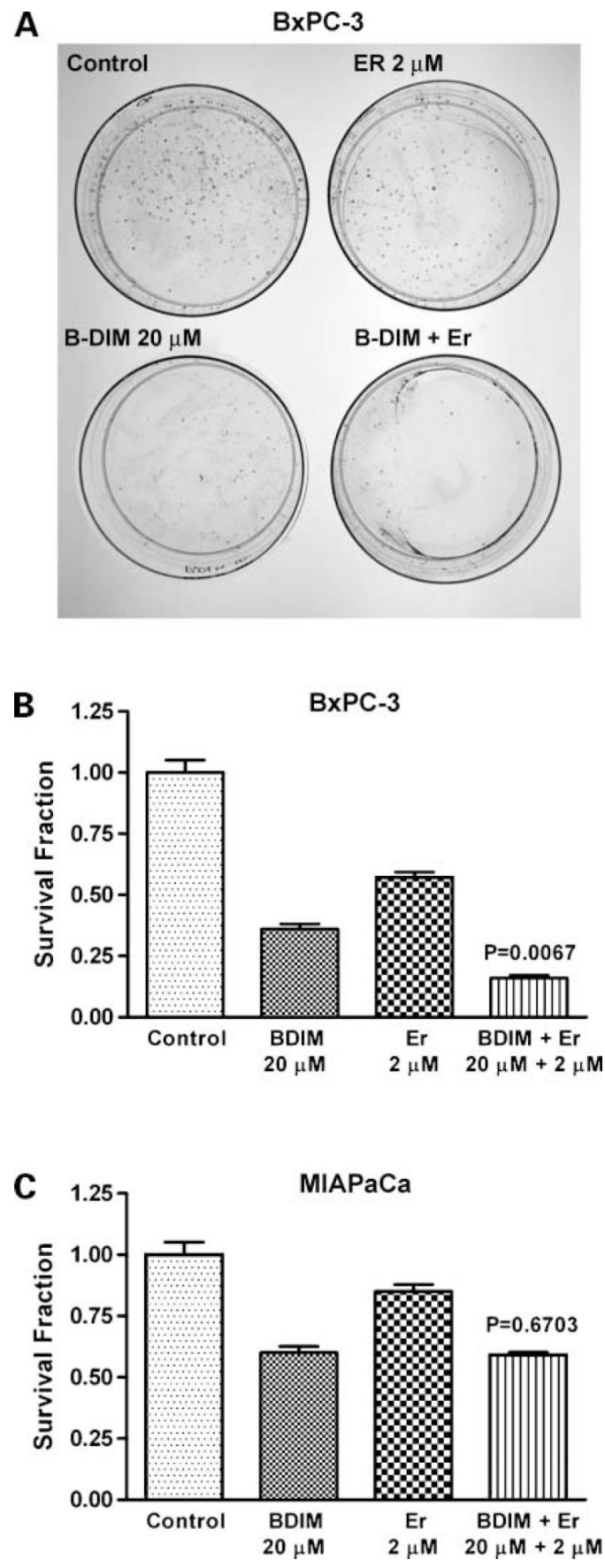

Figure 2.

Cell survival of human pancreatic cancer cell lines BxPC-3 and MIAPaCa cells. Cells treated with B-DIM $(20 \mu \mathrm{mol} / \mathrm{L})$, erlotinib $(2 \mu \mathrm{mol} / \mathrm{L})$, and the combination were evaluated by the clonogenic assay. A, photomicrographic difference in colony formation in BxPC-3 cells untreated and treated with erlotinib, B-DIM, and combination. There was a significant reduction in the colony formation in $\mathrm{BxPC}-3$ cells treated with the combination compared with cells treated with either drug alone (B). No such effect was seen with combination in MIAPaCa cells (C). $P$ values represent comparisons between cells treated by either B-DIM or the combination of both drugs using the paired $t$ test. 


\section{BxPC-3}

Figure 3.
MIAPaCa

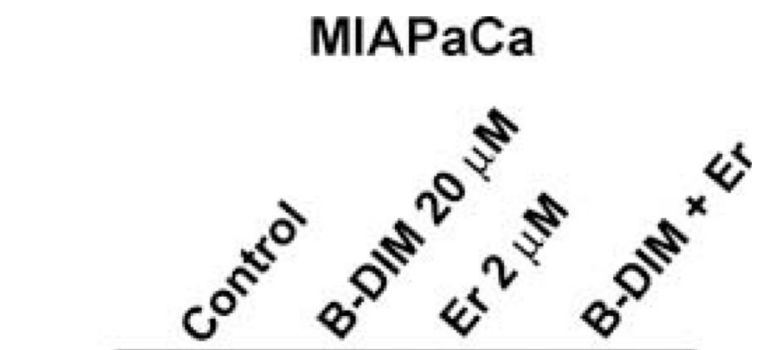

Survivin

Bcl-2

EGFR

pEGFR

C-IAP1

C-IAP2

PARP

Src

$\beta$-actin
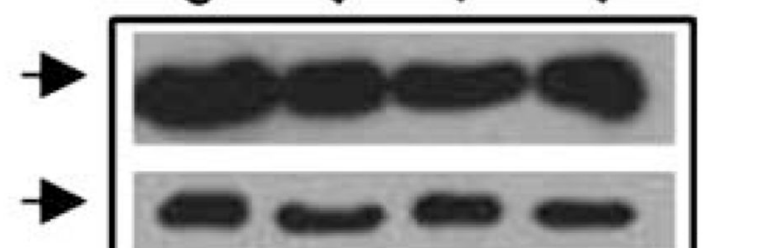

Bcl-xL
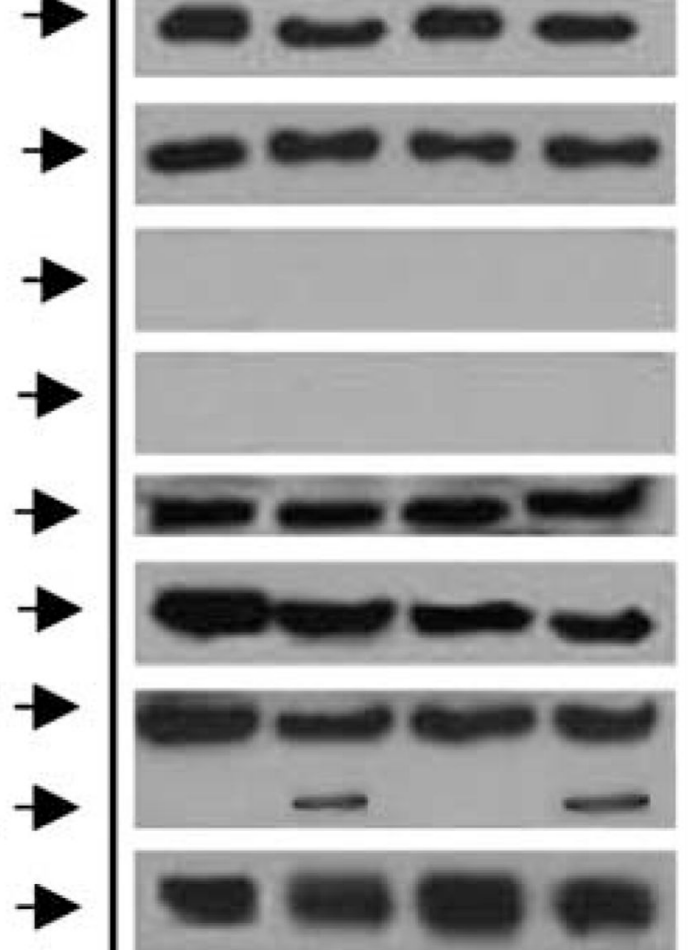

$\rightarrow$

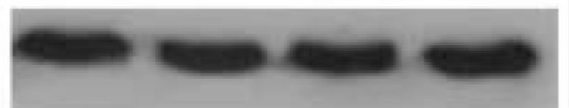

Expression of survivin, Bcl-2, Bcl-xL, EGFR, EGFR-pTyr ${ }^{1173}$, c-IAP1/2, PARP, and Src by Western blot analysis. BxPC-3 and MIAPaCa human pancreatic cell lines were treated with B-DIM $(20 \mu \mathrm{mol} / \mathrm{L})$, erlotinib $(2 \mu \mathrm{mol} / \mathrm{L})$, or the combination. $\beta$-Actin expression was used as protein loading control. Significant down-regulation of all proteins tested was observed in BxPC-3 cells treated with the combination compared with cells treated with either drug alone. No significant down-regulation of any protein was observed in MIAPaCa cells treated with or without combination of drugs. 
A

BxPC-3
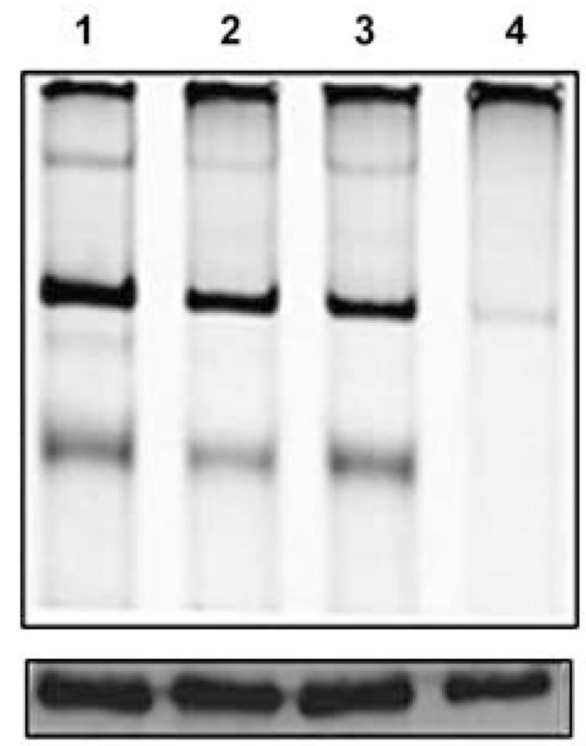
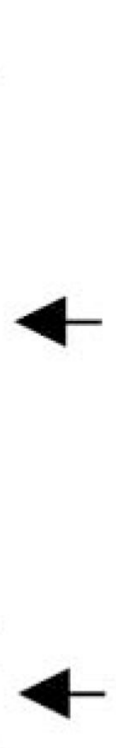
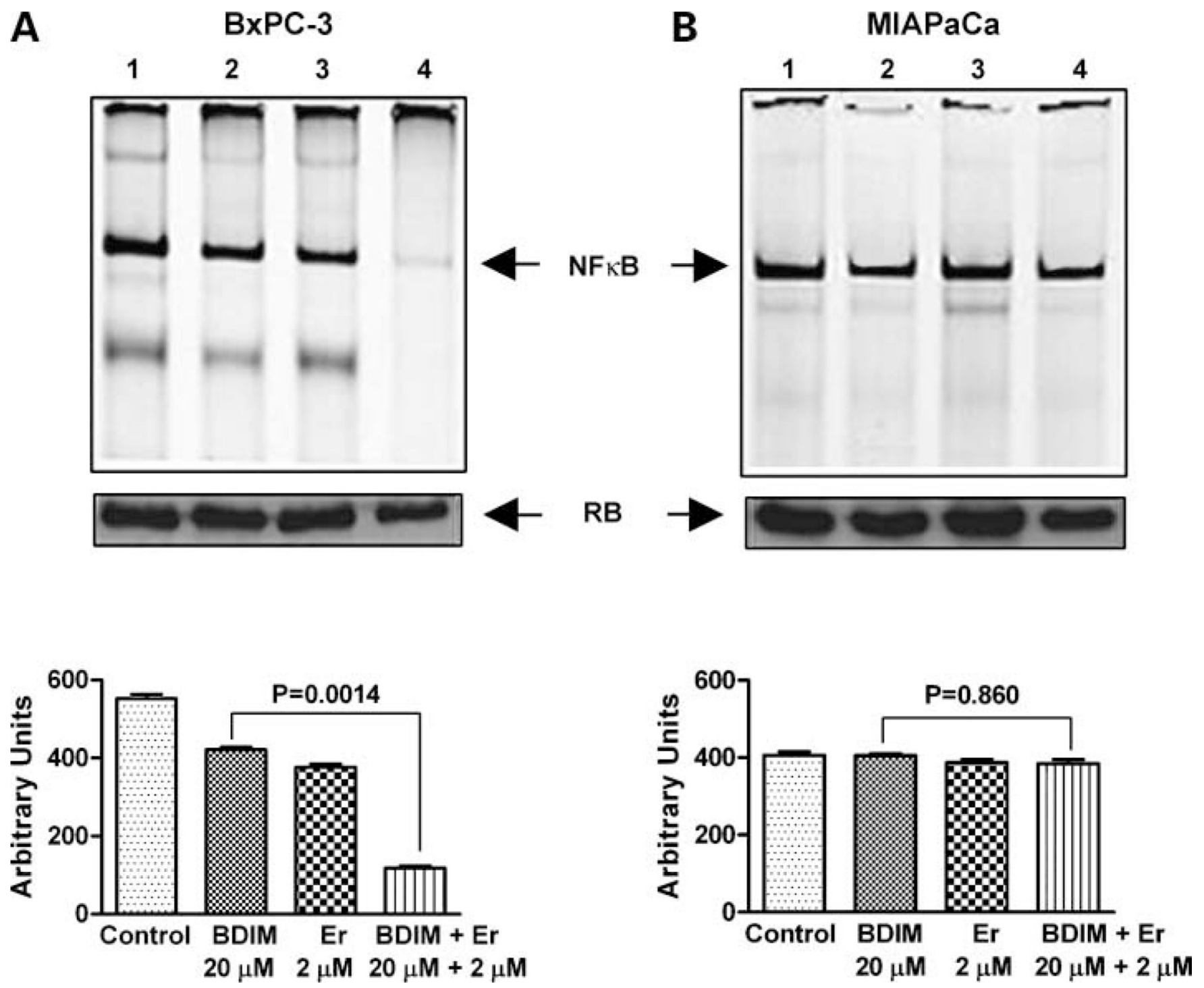

Figure 4.

Determination of NF-кB DNA-binding activity in nuclear extracts of BxPC-3 and MIAPaCa cells by EMSA. Untreated (lane 1), B-DIM (20 $\mu \mathrm{mol} / \mathrm{L}$; lane 2), erlotinib (2 $\mu \mathrm{mol} / \mathrm{L}$; lane 3), and B-DIM plus erlotinib (lane 4). Significantly greater down-regulation of NF- $\mu$ B DNAbinding activity was observed in cells treated with the combination compared with either drug alone in only BxPC-3 cells (A). No change was noted in NF-KB DNA-binding activity in MIAPaCa cells (B). Top, NF-KB DNA-binding activity; bottom, quantification. 
A

BxPC-3

MIAPaCa

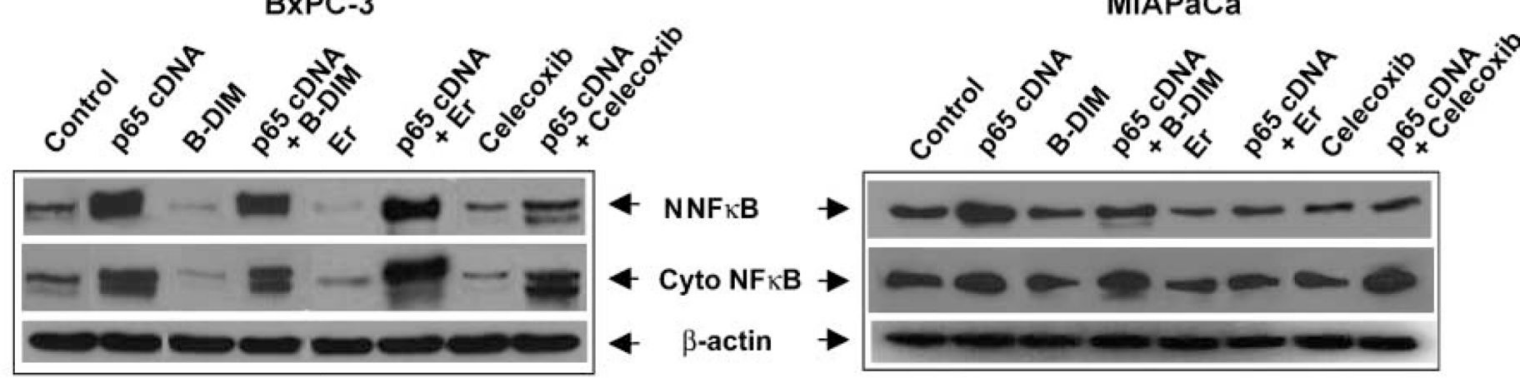

B
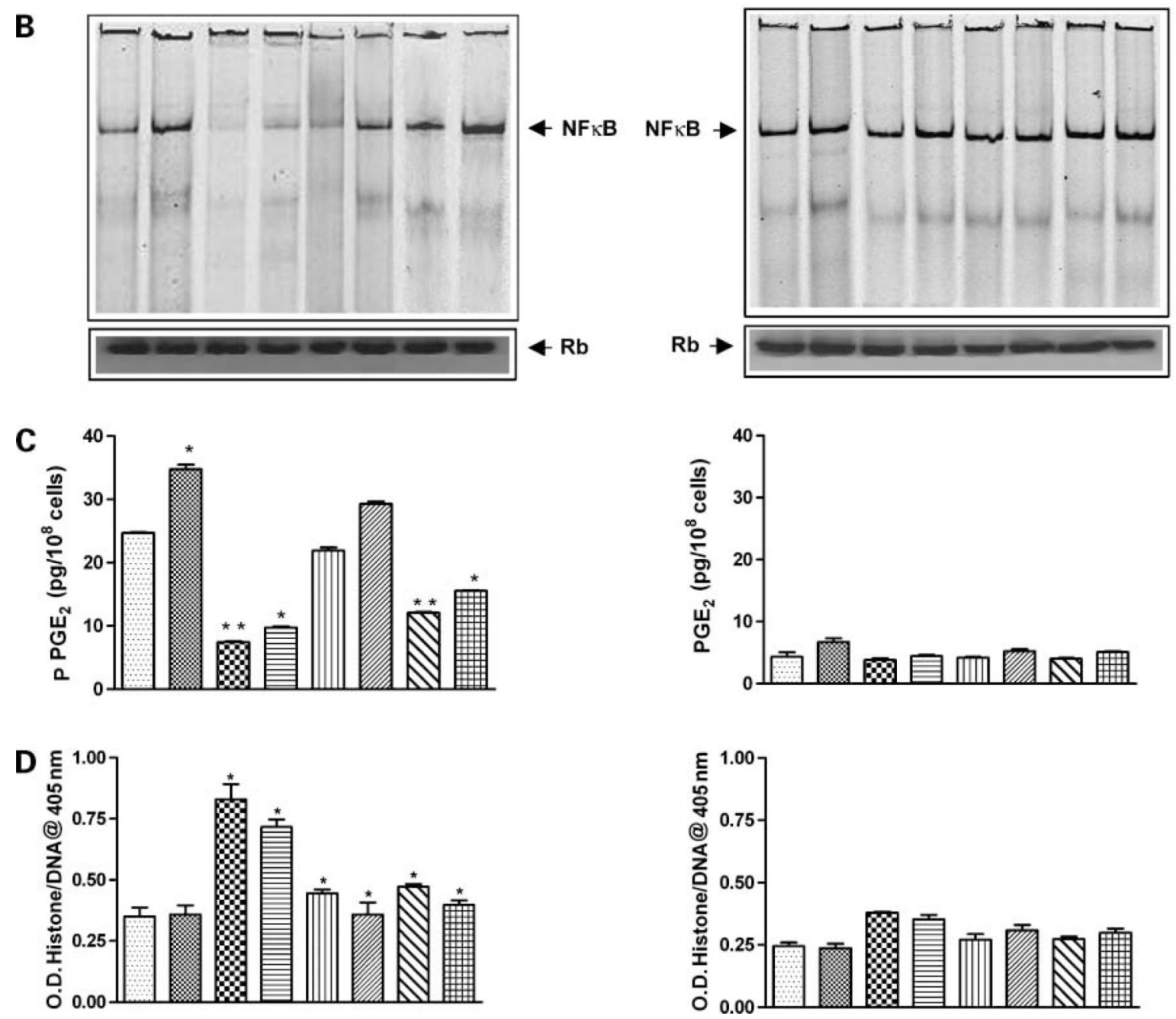

Figure 5.

Effect of p65 cDNA transfection in BxPC-3 and MIAPaCa cells. A, nuclear and cytoplasmic NF-KB p65 protein determined by Western blot analysis. B, NF-KB DNA-binding activity measured by EMSA. C, PGE 2 ELISA assay. D, apoptosis assay. BxPC-3 and MIAPaCa cells were transfected and then treated with erlotinib $(2 \mu \mathrm{mol} / \mathrm{L})$, B-DIM $(20 \mu \mathrm{mol} / \mathrm{L})$, or celecoxib $(5 \mu \mathrm{mol} / \mathrm{L})$ for $48 \mathrm{~h}$. Results showed that erlotinib, B-DIM, and celecoxib inhibited the 655 protein and NF-KB DNA-binding activity in BxPC-3 cells only, and a very minimal effect was seen in MIAPaCa cells (A and $\mathbf{B}$ ). BxPC-3 and MIAPaCa cells were transfected and then treated with erlotinib $10 \mathrm{nmol} / \mathrm{L}$, B-DIM $1 \mu \mathrm{mol} / \mathrm{L}$, or celecoxib 1 
$\mathrm{nmol} / \mathrm{L}$ for $48 \mathrm{~h}$ for $\mathrm{PGE}_{2}$ ELISA assay. No change in $\mathrm{PGE}_{2}$ level was noted when cells were treated with erlotinib alone $(P=0.084)$, but a significant reduction in $\mathrm{PGE}_{2}$ level was observed in BxPC-3 cells treated with B-DIM and celecoxib $(P=0.006$ and 0.005 ; C). Apoptosis results showed that the degree of apoptosis in BxPC-3 p65 cDNA-transfected cells treated with erlotinib $(P=0.034)$, B-DIM $(P=0.013)$, or celecoxib $(P=0.005)$ was much less compared with untransfected cells treated with erlotinib $(P=0.007)$, B-DIM $(P=$ $0.001)$, or celecoxib $(P=0.002 ; \mathbf{D})$. No such effect was observed in both $\mathrm{PGE}_{2}$ production and the degree of apoptosis in MIAPaCa cells. 


$$
\begin{aligned}
& \text { A ICR SCID mice (Female; 6-7 wks. } n=30 \text { ) } \\
& \text { Experimental Design: }
\end{aligned}
$$
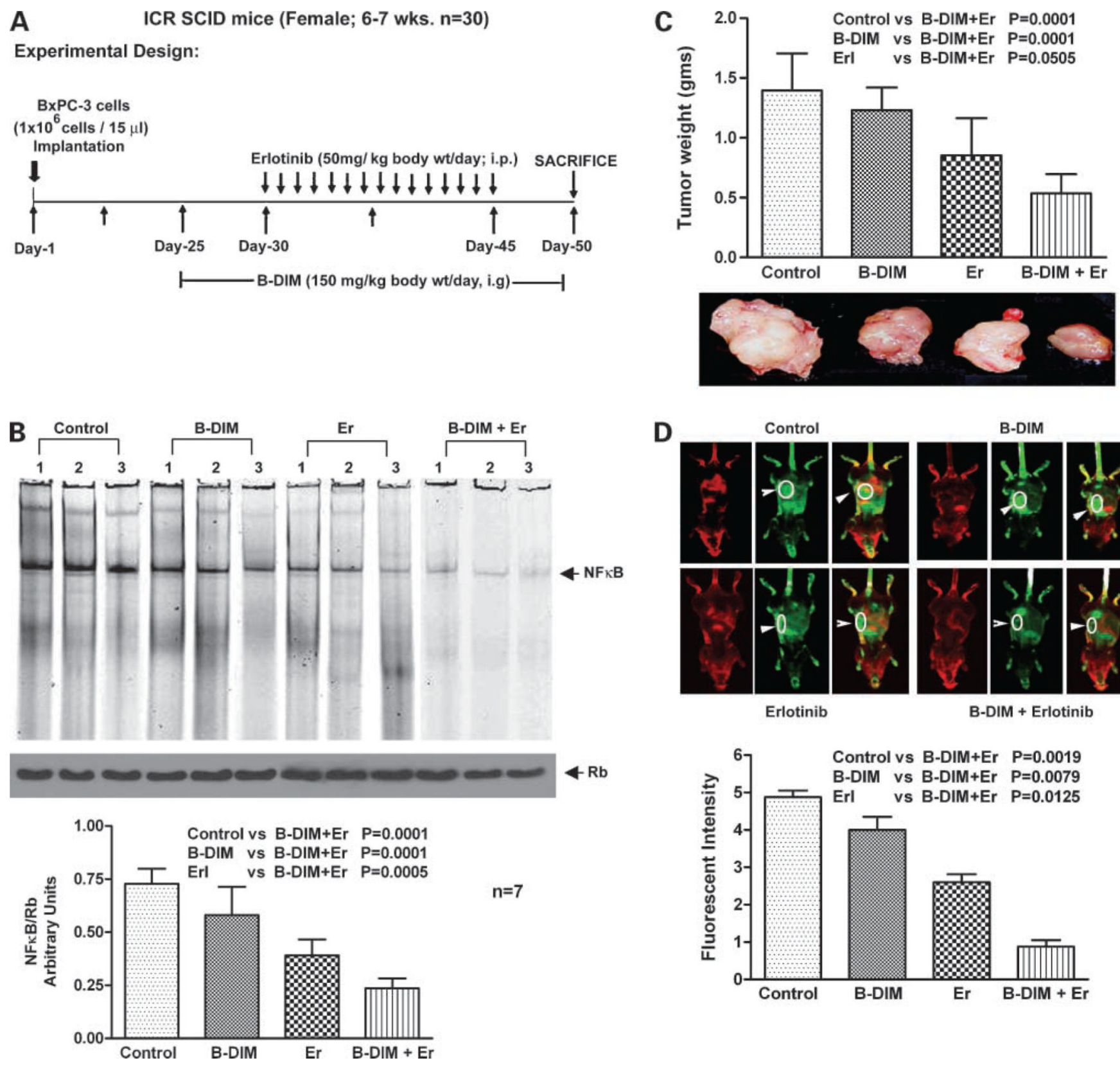

D

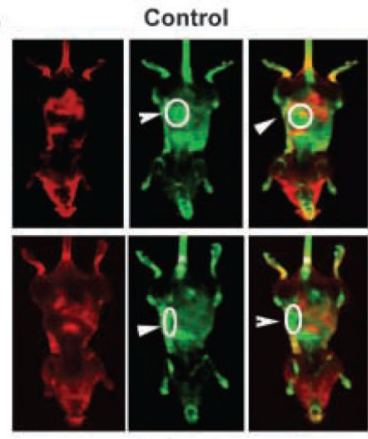

Erlotinib

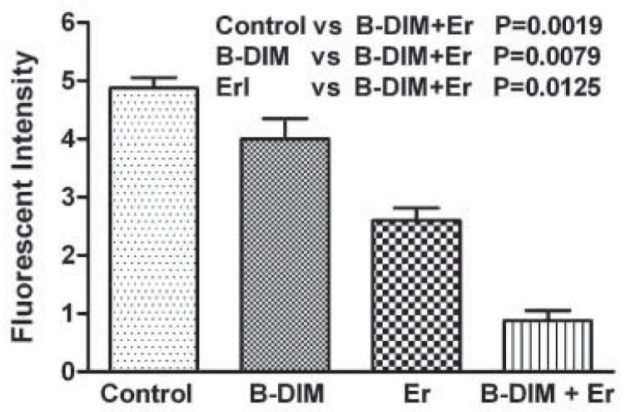

Figure 6.

A, flow chart representation of in vivo experimental design and treatment schedule. B, NFKB DNA-binding activity in nuclear extracts of randomly selected tumor tissues from each treatment groups of animals by EMSA. Bottom, quantification of all the animal data from each treatment groups $(n=7)$. C, changes in the isolated tumor weight showing efficacy of B-DIM and erlotinib combination. D, comparative image intensity from the captured images of randomly selected mice from each group showing lower fluorescent intensity of the IRDye-800CW EGF-targeting agent in the combination group of mice. Bottom, quantification of the image data. 
Table 1

MTT cell survival assay results

\begin{tabular}{lcc}
\hline Concentration $(\mathbf{m m o l} / \mathbf{L})$ & B-DIM $(\boldsymbol{\%})$ & Erlotinib $(\%)$ \\
\hline MTT cell survival assay with varying concentration in BxPC-3 cells & & \\
1 & 97 & 66 \\
2 & 90 & 50 \\
5 & 86 & 41 \\
10 & 78 & 37 \\
20 & 40 & \\
30 & 19 & \\
MTT cell survival assay with varying concentration in MIAPaCa cells & & \\
1 & 99 & 100 \\
2 & 95 & 90 \\
5 & 91 & 77 \\
10 & 80 & 70 \\
20 & 62 & \\
30 & 57 & \\
\hline
\end{tabular}

